\title{
Reform and Practice of Cultivating Innovative Talents in Agricultural Engineering Discipline
}

\author{
Bo Liu ${ }^{1, a}$ and Liangjie Dong ${ }^{2, b, *}$ \\ ${ }^{1,2}$ College of engineering and technology, Jilin Agricultural University \\ ${ }^{1,2}$ Xincheng Street 2888, Jilin Agricultural University, Changchun, Jilin Province 130118,PR China \\ 281867061@qq.com \\ * The Corresponding author
}

Key words: Agricultural engineering disciplines; Graduate students; Innovative talents; Training Mode

\begin{abstract}
Firstly, this paper analyzes the status quo of innovative talents training model in agricultural engineering disciplines. Secondly, it focuses on the analysis of the reform measures of innovative talents training mode, including reforming the personnel training program, reforming the innovative curriculum system and strengthening the construction of the mentor team and strengthening Innovation and talent level of the joint training and other content, and finally put forward after the reform of personnel training model brought about by a series of practical results.

In the fifth Plenary Session of the 18th CPC Central Committee, it was proposed that "we should vigorously promote the modernization of agriculture, accelerate the transformation of agricultural development mode, and take the road of agricultural modernization with efficient output, product safety, resource-saving and environment-friendly[1]" .Agricultural modernization mainly includes agricultural mechanization, technology production technology and agricultural industrialization and information technology and so on. The realization of agricultural modernization is inseparable from the talent. In China, graduate education is an important way to cultivate high-level innovative talents. At present, it is necessary to cultivate a large number of graduate students with practical ability and innovation ability to meet the requirements of modern agricultural development. How to cultivate the high-level innovation talents needed for agricultural modernization has become an urgent problem to be solved in the education of agricultural engineering subject in China [2].
\end{abstract}

\section{Analysis on the Cultivation of Innovative Talents in Agricultural Engineering Discipline}

Graduate Students Continue to Expand, Leading to a Series of Problems. With the continuous expansion of graduate education, and with the country on the status of postgraduate qualifications continue to improve, the number of graduate enrollment rising. Nowadays, graduate education has gradually changed from the previous elite education to popular education, which directly affects the quality of graduate students. At the same time, the number of graduate students increased, but the number of teachers did not increase the number of matching, resulting in insufficient teachers, leading to school education funding and other issues, resulting in graduate students innovative ability and practical ability.

The Traditional Graduate Training Mode Backward, Not Keep Up with Market Demand. In addition to the emphasis on basic disciplines of professional knowledge and skills and professional research ability, the emphasis on cultivating innovative talents is to pay more attention to the flexible application of talent knowledge and the ability of market adaptability. In the past, after graduating from the postgraduates of agricultural engineering, most of them went to colleges and universities, scientific research, civil servants and other institutions. The trend is that most graduates choose to go to productive enterprises. However, combined with the characteristics of agricultural engineering disciplines of graduate students and creative skills and other characteristics, the current training mode of graduate students more still stay in the cultivation of "formal graduate" level, that is, the school focus on postgraduate professional discipline training, passive of the subject or experimental practice of learning, and ignore the students take the initiative to explore 
learning, ignoring the students' initiative "research" ability and creative production practice ability. This is not conducive to the professional postgraduate comprehensive skills to improve, but also keep up with changes in market demand.

Tutor Team Constitute A Single. In the agricultural engineering disciplines as a graduate tutor's degree is generally a doctor, titles are almost associate professors and professors. The mentor's composition is almost always the school's "old school", which is constituted by the school's professional qualifications qualified teachers. In view of the practicality of agricultural engineering disciplines, the application of technical requirements is high, the current composition of the school tutor team is too simple, did not make full use of excellent off-campus resources, that is, outside the agricultural technology sector or related enterprises and technical personnel.

\section{The Agricultural Engineering Disciplines Graduate Talents Training Mode of Specific Reform Measures.}

Reform of Personnel Training Programs to Ensure the Quality of Graduate Students. In addition to the previous curriculum development, open-ended report, mid-term assessment, academic activities and paper work, but also should be based on the professional characteristics of agricultural engineering disciplines, the students into the grassroots or agricultural technical positions and other production practice practice Internship into the personnel training program. At the same time, in order to improve the research level of graduate students, the writing of literature and books, the writing of literature review and the writing of related essays should be stipulated. In addition, the research capacity of graduate students should also have a certain standard, that is, during the graduate study, the need to participate in or presided over a certain number of topics and successful subjects in order to successfully graduate. In addition, if the students in the practice of practice in the process of inventions or gains, you should give the appropriate incentive mechanism, including the accounting into the corresponding credits. Thus inspiring students' creative ability. In short, the school according to the needs of the social market, and constantly enrich the agricultural engineering disciplines of graduate training programs, thereby improving the graduate graduate academic research ability and innovative practical ability.

\section{Reform the Curriculum System, Improve Students' Creative Practical Ability.}

To establish a production enterprise-oriented curriculum system. Agricultural engineering disciplines on the requirements of talent is more practical technical ability. Therefore, the school in addition to professional basic courses, but also should be based on the needs of the social market, combined with the specific requirements of productive enterprises and research projects to focus on the content and evaluation methods, focusing on improving the scientific research capacity and innovative ability.

The construction of the whole fusion curriculum system. In the graduate curriculum system, remove the traditional first year of research study, the second and third year to study the boundaries of the subject, the two will be integrated together to become a full integration of the curriculum system[3].That is, the teaching of professional basic knowledge, in the first year focused on cultivating the professionalism of graduate students, teaching students to read and access to literature books, and will write literature review and other materials; But also the integration of the second year and the third teaching task, that is, students in the laboratory in the tutor and division brother's sister's help, clear their own experimental goals, and orderly to carry out their own experimental process. In addition, the subject of participation, research and practice internship links throughout the graduate students throughout the learning stage. Will improve the agricultural engineering disciplines of theoretical research ability and creative practice application ability closely.

\section{To Strengthen the Mentor Team Building, Enrich the Composition of the Mentor Team}

Content. At present, the training mechanism of postgraduates in agricultural engineering disciplines is to take the two mentor responsibility system. The two instructors are composed of the teachers of this institute, and have not fully utilized the talents of the productive technical departments outside the school. To this end, for the graduate tutor team building, which can be 
reformed as an internal mentor, an off-campus production technology department staff as an outside mentor. In order to facilitate the management, the implementation of the main mentor responsibility system. This approach can enrich the composition of the mentor team content, but also to make full use of outside the instructor rich practical experience and project resources and so on. At the same time, the selection of a number of young teachers to the productive technology enterprises to hire training to encourage teachers to participate in enterprise product development, technological transformation and enterprise management and other work to encourage teachers to make full use of enterprise research and practice platform to continuously improve their creative practical ability, For the outstanding performance of the teacher back to school, you can relax the qualifications of their qualifications and titles, allowing graduates to become a mentor[4].The reform and construction of the mentor team can enrich the composition of the mentor team, and better meet the market demand, so as to effectively improve the comprehensive ability of graduate students.

D. to Strengthen Intercollegiate Training to Promote Inter-school Exchanges and Cooperation. In the process of graduate training, we should pay attention to "going out" and "introduction", the school initiative and other institutions to obtain cooperation to encourage agricultural engineering disciplines graduate students to enter the unified institutions of other institutions to exchange learning, Between the joint training of talent. This new training policy can greatly promote the students' creative thinking ability, but also should encourage outstanding graduate students and teachers to visit domestic and foreign first-class universities, integration of multi-teaching resources, to cultivate high-quality high-capacity personnel services.

\section{Agricultural Engineering Disciplines Graduate Students Innovative Training Model Practice Effect.}

The Effective Training of Innovative High-level Talent. Agricultural Engineering Discipline Graduate Practice Innovation Education Base for the provincial and municipal scientific research research topics to cultivate a large number of innovative high-level talent, under the guidance of the school teachers and students, the professional graduate students involved in a large number of national innovative competition projects, and design related products, Which for students of innovation and practical ability to be fully developed.

To Promote Technological Progress in Productive Technology Enterprises. Through the school teachers to the productive technology enterprises to hire training and graduate students to practice the practice of training platform, the effective solution to the technical problems facing enterprises, but also repeatedly declared national, provincial and municipal scientific research projects. Greatly enriched the students' practical innovation ability. Related enterprises have also made the ability of technological research, and vigorously promote the process of agricultural modernization.

To Improve the Level of Agricultural Engineering Disciplines. The internal and external tutor system not only helps the students to improve the theoretical level, but also can enrich the students' practical skills, more convenient for students through the practice platform outside the practice, improve their creative ability, so as to improve their overall strength. According to the enterprise research project-oriented curriculum system, you can always meet the market demand for talent standards, training practical talents. The implementation of this series of reform measures has greatly improved the level of agricultural engineering disciplines in colleges and universities.

\section{Acknowledgements.}

13th Five - Year Plan" of Educational Science in Jilin Province (2016): Reform and Practice of Innovative Talents Training Model for Postgraduates Based on First - level Discipline. 


\section{References}

[1] http://bg.yjbys.com/gongzuobaogao/21935.html

[2] Yang Hua.Study and Practice on the Innovation Model of Postgraduate Education Model Based on Engineering Characteristics [J]. Henan Education (MID), 2010, (12): 3-4.

[3] Zong Li, Li Xiaoyu, Niu Zhiyou, Zhang Zhong.. Practice and thinking of innovative talents training mode for graduate students of Agricultural Mechanization Engineering [J]. Journal of Huazhong Agricultural University, 2005, (S1): 158-161.

[4] Cao Jie, Zhang Xiaoling, Wu Wenjie. Study and exploration of the postgraduate education and training mode of professional degree $[\mathrm{J}]$.Research On Education Tsinghua University, 2015, (01): 60-63. 